\title{
Fracture analysis of wild mammals in South Korea
}

\author{
Hyunkyu Jang' ${ }^{1}$ Jong-Moon Park ${ }^{1}$, Sohail Ahmed ${ }^{1}$, Seong-Hoon Seok ${ }^{2}$, Ho-Su Kim ${ }^{3}$, Seong-Chan Yeon ${ }^{1, *}$ \\ ${ }^{1}$ Department of Veterinary Clinical Sciences and Research Institute for Veterinary Science, Seoul Wildlife Center, \\ College of Veterinary Medicine, Seoul National University, Seoul 08826, Korea \\ ${ }^{2}$ Daegu Animal Medical Center, Daegu 42185, Korea \\ ${ }^{3}$ Busan Wildife Treatment Center, Busan 49435, Korea
}

\begin{abstract}
This study was conducted to evaluate and analyze fractures types in wild mammals in Korea. Wild mammals treated at 3 wildlife centers in Korea were included. Of the 63 cases included in this study, water deer was the most common species encountered with fractures. We determined 85 different fracture sites, with maximum lumber vertebral fractures followed by femoral, tibial and pelvic fractures. External skeletal fixator (ESF)-intramedullary (IM) pin (IM+ESF tie-in fixation) was the most common method applied for the surgical treatment of mammals. Lumbar vertebrae and femur were the most common bones involved. The findings of this study are expected to provide information for veterinarians regarding the frequency and characteristics of fractures in wild mammals and serve as a basic database for the types and outcomes of fractures in wild mammals.
\end{abstract}

Keywords: mammals, Korea, bone, surgery

*Corresponding author

Seong-Chan Yeon

Department of Veterinary Clinical Sciences and Research Institute for Veterinary Science, Seoul Wildlife Center, College of Veterinary Medicine, Seoul National University, 1 Gwanak-ro, Gwanak-gu, Seoul 08826, Korea

Tel: $+82-2-880-1216$

Fax: +82-2-876-8662

E-mail: scyeon1@snu.ac.kr

ORCID:

Hyunkyu Jang

https://orcid.org/0000-0001-7844-1816

Jong-Moon Park

https://orcid.org/0000-0002-0393-0639

Sohail Ahmed

https://orcid.org/0000-0001-6299-2031

Seong-Hoon Seok

https://orcid.org/0000-0003-0719-8665

Ho-Su Kim

https://orcid.org/0000-0002-6278-3325

Seong-Chan Yeon

https://orcid.org/0000-0002-2490-6291

Conflict of Interest

The authors declare no conflicts of interest.

Received: May 8, 2019

Revised: September 25, 2019

Accepted: October 17, 2019

\section{Introduction}

A fracture is defined as the dissolution of bony continuity, with or without displacement of fragments. Torn vessels, lacerated periosteum, contused nerves and bruised muscles, along with tissue damage of varying degrees, normally accompany fractures [1]. Hence, fractures remain a challenging problem for domesticated animals as well as wild mammals.

In wild animal orthopedics, fracture of the long bone is most commonly encountered. The prevailing occurrence of high energy traumas that lead to fractures is progressively severe to treat, due to significant excess of kinetic energy [2]. Comminuted fractures resulting from such high energy trauma are common in wildlife and also they require immediate surgical intervention. These are only those patients that survived the painful episode to enable subsequent surgical treatment. It is likely that significantly sufficient trauma that fractures the cranial bone is frequently associated with lethal trauma to the head. Similarly, trauma to the caudal half of the animal would be more prone to produce life threatening injuries. It is probable that mammals impending trauma approaching (automobiles), they expose their hindquarters to bear the major force of the impact.

Fracture treatments of injured mammals are important for their survival. The ideal objective of fracture treatment is to completely rehabilitate the patient in the shortest time possible [3]. There are several surgical methods including bone plate, intramedullary (IM) pins, and external skeletal fixation (ESF) is the method of choice for treating fractures in mammals [3]. Successful fracture treatment comprises a perfectly aligned bone of full length having solidly united joints that are freely movable to their fullest range, and normal musculature, innervations and integument surrounding the site of the previous fracture [3-5].

The expected outcome of a fracture is bone healing, defined as the functional stage of bone factors, such as degree of the adjacent soft tissue, the displacement of the fracture ends, and the degree of comminuting. Age of the patient and the presence of co-morbidities are other factors that influence selecting the method for the stabilization of the fracture $[6,7]$. 
Repair of bone fracture in wild mammals remains a challenge for the orthopedic surgeon. The prognosis and surgical challenges are directly related to facilities in wildlife centers and management of the patient by veterinarians $[8,9]$.

Several studies have reported fracture analysis of small animals and other mammals, but not wild mammals. Reports on avian orthopedics have proved useful for fracture treatments [10], and studies on fractures in deer and few wild mammals have been published. However, studies on the distribution of fracture, treatments, and outcomes of fracture management are minimal, and none have been reported in Korea to date.

This study is therefore aimed to present fractures analysis in wild mammals, distribution of fractures sites in different organs, and application of different surgical treatments for fracture recovery in the wildlife centers, in the period 2016 to 2019.

\section{Materials and Methods}

Data of wild mammals were collected from Seoul, Gyeongnam, and Busan Wildlife Centers in South Korea, from 2016 to 2019. The collected data include age, species, fracture types, treatment, radiographs, and outcomes. In this study, records were available for 63 animals having 85 fracture sites that underwent repair using different surgical techniques. Records were reviewed based on history, fracture location, and type of surgical repair technique. Data was then analyzed and compared with previous studies to make useful for wild mammals.

All the animals evaluated in this study were mostly wild animals belonging to three species: raccoon dog, water deer, and Siberian weasel. Different fracture sites were categorized into their respective types for analysis and treatment. Distribution of fracture sites was also evaluated according to the animal species. Data was further categorized according to the bones involved, i.e., mandible, humerus, radius, ulna, femur, tibia, fibula, pelvis, digit, vertebrae, and ribs.

Depending on the type of surgical invasion, site of fracture and outcome of treatments, the animals were classified as either hospitalized, euthanized, death after surgery, or reintroduced into wild. Four types of surgical treatments were implemented: bone plate, cast, IM pins, and ESF+IM pins. We further determined treatment techniques used to repair fracture and prognosis of wild mammals after surgical invasion. Follow-up information related with outcome of treatment was based on radiographic and physical examination by veterinarians.

\section{Results}

\section{Distribution of species}

Three species were presented among 85 fractures sites. Water deer $(n=44,69.8 \%)$ were the most common species, followed by raccoon $\operatorname{dog}(n=16,25.4 \%)$, and Siberian wea- sel $(n=3,4.8 \%)$. The total number of animals were 63 having different fractures.

\section{Distribution of age}

There were three categories based on the age of mammals that accounted for the fractures: $<1$ year, $1<\mathrm{x}<2$ years and $>2$ years. Higher incidence of fractures confirmed and treated in wildlife centers belonged to the $>2$ years group $(n=43$, $68.2 \%), 1<\mathrm{x}<2$ years $(\mathrm{n}=10,15.9 \%)$, and less than 1 year $(\mathrm{n}=10,15.9 \%)$ as given in Table 1 .

\section{Sites of fracture}

A total of 85 fracture sites were categorized (Table 2). Lumbar vertebrae (18 cases, $21.1 \%$ ) was the most common site of fracture (Fig. 1B and C), followed by the femur (13 cases, 15.3\%; Fig. 1D), tibia and pelvis ( 8 cases, $9.4 \%$ each), and radius ( 7 cases, $8.2 \%$ ). Frequency of fractures were lower for humerus ( 5 cases), ulna ( 5 cases), carpometacarpus ( 5 cases), fibula (4 cases), tarsometatarsus ( 4 cases), ribs ( 3 cases), mandible ( 2 cases), and sacrum (1 case). Fig. 1 showed radiographs of raccoon dog, water deer, and Siberian weasel. Distribution of fractures sites by species is given in Table 3.

Table 1. Distribution of age

\begin{tabular}{cc}
\hline \hline \multicolumn{1}{c}{ Species } & Values \\
\hline$<1$ year & $10(15.9)$ \\
$>2$ years & $43(68.2)$ \\
$1<\mathrm{x}<2$ years & $10(15.9)$ \\
Total & $63(100)$ \\
\hline
\end{tabular}

Values are presented as number (\%).

Table 2. Distribution of fractures sites

\begin{tabular}{lc}
\hline \hline \multicolumn{1}{c}{ Fracture site } & Values \\
\hline Mandible & $2(2.4)$ \\
Humerus & $5(5.9)$ \\
Radius & $7(8.2)$ \\
Ulna & $5(5.9)$ \\
Carpometacarpus & $5(5.9)$ \\
Femur & $13(15.3)$ \\
Tibia & $8(9.4)$ \\
Fibula & $4(4.7)$ \\
Tarsometatarsus & $4(4.7)$ \\
Pelvis & $8(9.4)$ \\
Thoracic vertebrae & $2(2.3)$ \\
Lumbar vertebrae & $18(21.1)$ \\
Sacrum & $1(1.1)$ \\
Ribs & $3(3.5)$ \\
Total & $85(100)$
\end{tabular}

Values are presented as number (\%). 

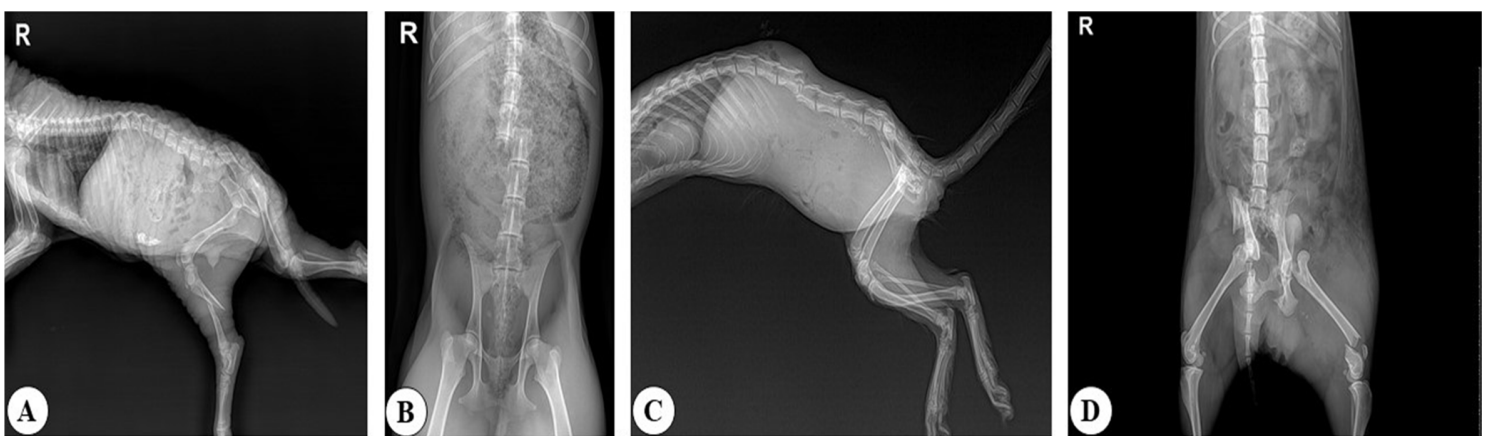

Fig. 1. Pre-operative radiographs. (A) Lateral radiograph of Raccoon dog (Nyctereutes procyonoides), revealing right tibial fracture. (B) Ventrodorsal radiograph of water deer (Hydropotes inermis), revealing 3rd lumbar vertebral fracture. (C) Lateral radiograph of Siberian weasel (Mustela sibirica), revealing 3rd lumbar vertebral fracture. (D) Ventrodorsal radiograph of Raccoon dog ( $N$. procyonoides), revealing left femoral and pelvic fracture. R, right.

Table 3. Distribution of fractures sites by species

\begin{tabular}{lccc}
\hline \hline \multicolumn{1}{c}{ Fracture site } & Raccoon dog & Siberian weasel & Water deer \\
\hline Mandible & $0(0.0)$ & $0(0.0)$ & $2(3.4)$ \\
Humerus & $1(4.3)$ & $0(0.0)$ & $4(6.9)$ \\
Radius & $2(8.7)$ & $0(0.0)$ & $5(8.6)$ \\
Ulna & $2(8.7)$ & $0(0.0)$ & $3(5.2)$ \\
Carpometacarpus & $0(0.0)$ & $0(0.0)$ & $5(8.6)$ \\
Femur & $5(21.7)$ & $1(25.0)$ & $7(12.1)$ \\
Tibia & $1(4.3)$ & $1(25.0)$ & $6(10.3)$ \\
Fibula & $14.3)$ & $1(25.0)$ & $2(3.4)$ \\
Tarsometatarsus & $0(0.0)$ & $0(0.0)$ & $4(6.9)$ \\
Pelvis & $6(26.1)$ & $0(0.0)$ & $2(3.4)$ \\
Thoracic vertebrae & $2(8.7)$ & $0(0.0)$ & $0(0.0)$ \\
Lumbar vertebrae & $0(0.0)$ & $1(25.0)$ & $17(29.3)$ \\
Sacrum & $1(4.3)$ & $0(0.0)$ & $0(0.0)$ \\
Ribs & $2(8.7)$ & $0(0.0)$ & $1(1.7)$ \\
Total & $23(100)$ & $4(100)$ & $58(100)$ \\
\hline
\end{tabular}

Values are presented as number (\%).

Table 4. Treatment of fractures in mammals

\begin{tabular}{lcc}
\hline \hline \multicolumn{1}{c}{ Treatment } & Raccoon dog & Water deer \\
\hline Bone plate & - & $2(4.5)$ \\
Cage rest & $13(81.2)$ & $31(70.5)$ \\
IM pin & $2(12.5)$ & $3(6.8)$ \\
IM pin+ESF & - & $6(13.6)$ \\
Cast & $1(6.3)$ & $2(4.5)$ \\
Total & $16(100)$ & $44(100)$ \\
\hline
\end{tabular}

Values are presented as number $(\%)$.

\section{Surgical treatments}

Surgical treatments included in this study were cage rest, bone plate, IM pin, ESF+IM pins (tie-in fixation), and cast treatments. In case of raccoon dogs, cage rest was the most common treatment $(13,81.2 \%)$, followed by IM pin (2,
$12.5 \%)$, and cast $(1,6.3 \%)$. Totally 44 water deer were treated by 5 different methods (Table 4): cage rest (31, 70.5\%), ESF+IM pins $(6,13.6 \%)$, IM pin $(3,6.8 \%)$, bone plate $(2$, $4.5 \%)$, and cast $(2,4.8 \%)$. The 3 weasels treated were cage rested.

\section{Prognosis after surgery}

Outcomes for the 44 water deer were 25 (57\%) mortalities, euthanasia (11 cases, 25\%), and dead on arrival (DOA) and released animals were 3 cases each (6.8\%). Only 1 case was hospitalized (2.2\%). Among the 16 cases of raccoon dogs examined, euthanasia was the prevalent outcome $(9$ case, $56.3 \%)$, followed by release $(4,25 \%)$, death $(2,12.5 \%)$ and hospitalization $(1,6.2 \%)$, as given in Table 5. All 3 weasels were euthanized. No lameness was observed in a raccoon dog (Nyctereutes procyonoides) after rehabilitation and recovery from left radius and ulna fracture treated by using 
Table 5. Prognosis after surgery in mammals

\begin{tabular}{lcc}
\hline \multicolumn{1}{c}{ Outcome } & Raccoon dog & Water deer \\
\hline DOA & $0(0)$ & $3(6.8)$ \\
Release & $4(25)$ & $4(9)$ \\
Euthanasia & $9(56.3)$ & $11(25)$ \\
Hospitalization & $1(6.2)$ & $1(2.2)$ \\
Death & $2(12.5)$ & $25(57)$ \\
Total & $16(100)$ & $44(100)$ \\
\hline
\end{tabular}

Values are presented as number $(\%)$.
IM pin fixation. Prognosis of fractures by species and surgical management is given in Table 6 .

\section{Radiographic evaluation of fracture and surgical treatment}

Craniocaudal views were obtained immediately at postfracture fixation. Subsequently, a number of radiographs were exposed till recovery and proper union of bones. Radiographic postoperative examination revealed unification of bone fragments and proper alignment.

Lateral radiograph of Raccoon dog ( $N$. procyonoides)

Table 6. Prognosis of fractures by species and surgical management

\begin{tabular}{|c|c|c|c|c|c|}
\hline \multirow{2}{*}{ Species/management } & \multicolumn{2}{|c|}{ Dead } & \multirow{2}{*}{ Hospitalized } & \multirow{2}{*}{ Full recovery } & \multirow{2}{*}{ Total } \\
\hline & Post-operative death & Euthanasia & & & \\
\hline Raccoon dog & $2(14.3)$ & $7(50)$ & $1(7.1)$ & 4 (28.6) & 14 \\
\hline Cage rest & $2(18.2)$ & 7 (63.6) & $0(0.0)$ & $2(18.2)$ & 11 \\
\hline Cast & $0(0.0)$ & $0(0.0)$ & $0(0.0)$ & $1(100.0)$ & 1 \\
\hline IM pin & $0(0.0)$ & $0(0.0)$ & $1(50.0)$ & $1(50.0)$ & 2 \\
\hline Siberian weasel & $0(0.0)$ & $3(100.0)$ & $0(0.0)$ & $0(0.0)$ & 3 \\
\hline Cage rest & $0(0.0)$ & $3(100.0)$ & $0(0.0)$ & $0(0.0)$ & 3 \\
\hline Water deer & $28(66.7)$ & $10(23.8)$ & $1(2.4)$ & $3(7.1)$ & 42 \\
\hline Bone plate & $2(100.0)$ & $0(0.0)$ & $0(0.0)$ & $0(0.0)$ & 2 \\
\hline Cage rest & $18(62.1)$ & $10(34.5)$ & $0(0.0)$ & $1(3.4)$ & 29 \\
\hline Cast & $2(100.0)$ & $0(0.0)$ & $0(0.0)$ & $0(0.0)$ & 2 \\
\hline IM pin & $2(66.7)$ & $0(0.0)$ & $1(33.3)$ & $0(0.0)$ & 3 \\
\hline IM pin+ESF & $4(66.7)$ & $0(0.0)$ & $0(0.0)$ & $2(33.3)$ & 6 \\
\hline
\end{tabular}

Values are presented as number $(\%)$.
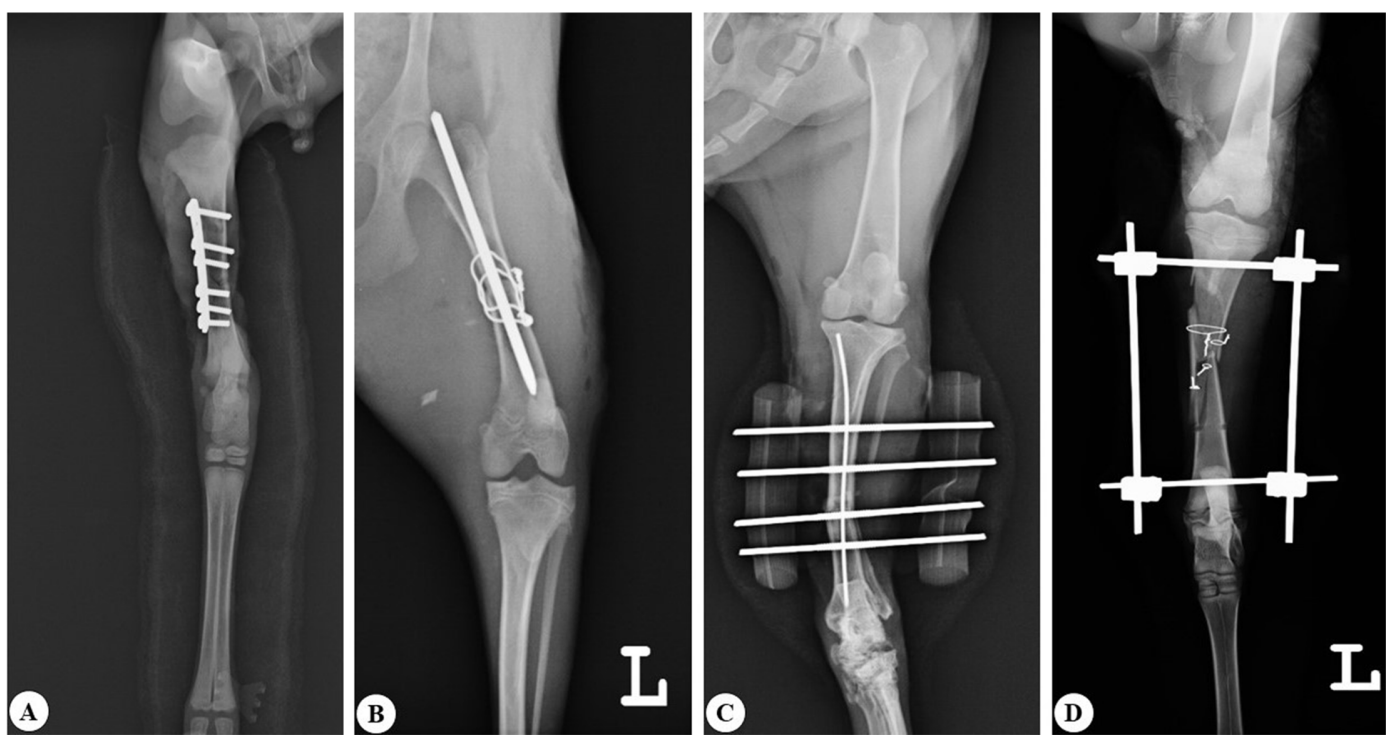

Fig. 2. Post-operative radiographs. (A) Craniocaudal radiograph of water deer (Hydropotes inermis), showing repaired right femur with bone plate fixation. (B) Craniocaudal radiograph of raccoon dog (Nyctereutes procyonoides), showing fractured left femur is fixated by using IM pin and cerclage wire. (C) Craniocaudal radiograph of raccoon dog ( $N$. procyonoides), showing fractured left tibia is repaired by using IM pin and external skeletal fixator. (D) Craniocaudal radiograph of water deer (H. inermis), showing repaired left tibia with ESF. L, left; IM, intramedullary. 
revealed complete oblique fracture at the diaphysis of the right tibia with caudal displacement of the distal end of the proximal fragment of the right tibia as shown in Fig. 1A. Ventrodorsal radiograph of water deer (Hydropotes inermis) revealed marked dislocation of $3 \mathrm{rd}$ lumbar vertebra to the left side, consistent with vertebral fracture as shown in Fig. 1B. Lateral radiograph of Siberian weasel (Mustela sibirica) revealed ventral deviation of the 3rd lumbar vertebra with mineral fragments at the intervertebral foramen between 2 nd and 3 rd lumbar vertebrae, which is consistent with vertebral fracture as shown in Fig. 1C. Ventrodorsal radiograph of Raccoon dog (N. procyonoides) revealed disruption of the normal box-like appearance of the pelvis by right iliac and left ischial fractures. There were also luxation of the left femoral head and complete transverse fracture at the distal metaphysis of the left femur as shown in Fig. 1D.

Post-operative radiographs of water deer (H. inermis), showed repairing by using bone plate fixation or ESF as shown in Fig. 2A and D. Post-operative radiographs of raccoon dog ( $N$. procyonoides), showed fixation by using IM pin and cerclage wire or IM pin and ESF as shown in Fig 2B and $\mathrm{C}$.

\section{Discussion}

Research of bone fractures in wild mammals is complicated since the specimens studied may not accurately represent the situation in wild. Field workers have difficulty in observing mammals in their natural state, and may miss some fractures, especially minor ones and those occurring in juveniles [11].

More fractures were observed during late summer and early autumn i.e., June, July and November. Many comminuted fractures were caused by collision or hitting by vehicles. Fractures were seen mostly in the young and adult deer [12]. Fractures and other musculoskeletal fractures were predominant $(70 \%)$ compared to other soft tissue damages (30\%) [13].

In a previous study, 14 water deer were treated. During transportation, $50 \%$ were not sedated, while remaining $50 \%$ were sedated. Seven animals were released after surgery and recovery, but the remaining died at different intervals after surgery. Of the 7 released animals, 6 were sedated during and after surgery [14]. The results were similar to the present study. This indicates that sedation may be helpful in reducing stress and preventing adverse effects of stress [15].

To date, there have been no studies evaluating the fracture types in wild mammals. In the present study, a higher percentage of fractures were observed in long bones such as femur, tibia, humerus, radius, and ulna. The number of bone fragments and extent of damage to the adjacent soft tissues were both affected by the velocities of the forces causing the fracture. Low velocity forces resulted in single fractures, whereas high velocity forces caused multiple fractures [10].

Axial skeleton fractures are common. i.e., vertebrae, pelvis. We confirmed several cases of vertebral fractures as well as pelvic fractures. In this study, the highest percentage of fractures was found in the lumbar vertebrae $(21.17 \%)$, while pelvic fractures accounted for $9.41 \%$. Depending on species, locations of commonly occurred fracture are different. Considering long bones, femur was the most common long bone involved in fractures, followed by tibia, and radius. The frequency of fractures of humerus ( 5 cases), ulna ( 5 cases), carpometacarpus ( 5 cases), fibula (4 cases), tarsometatarsus (4 cases), ribs ( 3 cases), mandible ( 2 cases), and sacrum ( 1 case) were low.

Selection of appropriate surgical materials and methods for the treatment of fractures in wild mammals is challenging. Treatment of fractures in wild mammals chiefly involves the use of bone plate, IM pins, and IM pins+ESF. In the present study, IM pins were applied in 2 of the 16 surgically treated raccoon dogs, whereas water deer received IM pins $(6.8 \%)$ as well as IM pins+ESF (13.6\%). Of the 63 mammals that were surgically treated in the present study, 8 exhibited recoveries, while 27 died. According to physical status, mammals were euthanized or kept hospitalized during and after surgical treatment.

In the present study, a high percentage of raccoon dogs were released in the wild (25\%), whereas water deer showed a very poor outcome of fracture management. The reasons for the low rate of release into the wild include stress of surgical intervention as well as delayed treatment due to a long interval between the time of injury and recovery.

Stress is caused by sudden capture with forceful muscular exertion or fear during transportation or surgical treatment, resulting in psychological and physical stress in animals. This complication is diagnosed by depression, metabolic acidosis, lack of coordination, and death in ungulates, especially in deer $[15,16]$. In the present study, all Siberian weasels were euthanized and also water deer releasing rate was very low. However, raccoon dogs were kept hospitalized (6.2\%) and released $(25 \%)$, based on the surgical outcome.

In conclusion, this is the first study to evaluate fractures analysis in wild mammals in Korea. The incidence of fracture was more in water deer than other mammals. Lumbar vertebrae and femur were the most common bones involved. The most frequently applied surgical treatment was IM pins+ESF. The findings of this study are expected to provide information for veterinarians regarding the frequency and characteristics of fractures in wild mammals, and serve as a basic database for the treatment of fractures in wild mammals in Korea.

\section{Acknowledgments}

This research was supported by Seoul, Gyeongnam, and Busan Wild Life Animal Centers.

\section{References}

1. Mahajan T, Ganguly S, Para PA. Fracture management in 
180 Hyunkyu Jang, Jong-Moon Park, Sohail Ahmed, Seong-Hoon Seok, Ho-Su Kim, Seong-Chan Yeon

animals: a review. J Chem Biol Phys Scs. 2015;4:4053-4057.

2. Pires RE, Reis FB, Simões CE, Santos LE, Rodrigues VB, Andrade MA, Pires Neto PJ. Femoral shaft fracture: reproducibility of AO-ASIF and Winquist classifications. Acta Ortop Bras 2010;18:197-199.

3. Tunio A, Jalila A, Meng CY, Shameha I. Experimental fracture healing with external skeletal fixation in a pigeon ulna model. J Adv Vet Anim Res 2014;1:58-64.

4. Allgöwer M, Spiegel PG. Internal fixation of fractures: evolution of concepts. Clin Orthop Relat Res 1979;138:26-29.

5. Hampton OP, Fitts WT. Open Reduction of Common Fractures. Vol. 2. Grune \& Stratton, New York, 1959.

6. Giannoudis PV, MacDonald DA, Matthews SJ, Smith RM, Furlong AJ, De Boer P. Nonunion of the femoral diaphysis. The influence of reaming and non-steroidal anti-inflammatory drugs. J Bone Joint Surg Br 2000;82:655-658.

7. Sousa CP, Dias IR, Lopez-Peña M, Camassa JA, Lourenço PJ, Judas FM, Gomes ME, Reis RL. Bone turnover markers for early detection of fracture healing disturbances: a review of the scientific literature. An Acad Bras Cienc 2015;87: 1049-1061.

8. Harasen G. Common long bone fractures in small animal practice--part 1. Can Vet J 2003;44:333-334.

9. Horstman CL, Beale BS, Conzemius MG, Evans R R. Biological osteosynthesis versus traditional anatomic recons- truction of 20 long-bone fractures using an interlocking nail: 1994-2001. Vet Surg 2004;33:232-237.

10. Kim T, Kwon Y. Bone fractures in raptors in the DaeguGyeongbuk region. J Vet Clin 2016;33:261-265.

11. Bulstrode $\mathrm{C}$. What happens to wild animals with broken bones. Iowa Orthop J 1990;10:19.

12. Martinez-Pastor F, Guerra C, Kaabi M, Garcia-Macias V, de Paz P, Alvarez M, Herraez P, Anel L. Season effect on genitalia and epididymal sperm from Iberian red deer, roe deer and Cantabrian chamois. Theriogenology 2005;63:18571875.

13. Rossi I, Lamberti P, Mauri L, Apollonio M. Male and female spatial behaviour of roe deer in a mountainous habitat during pre-rutting and rutting period. J Mt Ecol 2001;6:1-6.

14. Nisbet HO, Ozak A, Yardimci C, Sirin YS. Treatment results of traumatic injuries in 20 roe deer (Capreolus capreolus): a retrospective study. Kafkas Univ Vet Fak Derg 2010;16:617622.

15. Montané J, Marco I, Manteca X, López J, Lavín S. Delayed acute capture myopathy in three roe deer. J Vet Med A Physiol Pathol Clin Med 2002;49:93-98.

16. Morton DJ, Anderson E, Foggin CM, Kock MD, Tiran EP. Plasma cortisol as an indicator of stress due to capture and translocation in wildlife species. Vet Rec 1995;136:60-63. 